\title{
Recognition Memory and Familiarity Judgments in Severe Amnesia: No Evidence for a Contribution of Repetition Priming
}

\author{
Craig E. L. Stark \\ University of California, San Diego
}

\author{
Larry R. Squire \\ Veterans Affairs Medical Center, San Diego, \\ and University of California, San Diego
}

\begin{abstract}
The amnesic patient E.P. has demonstrated normal levels of repetition priming and at-chance recognition performance (S. B. Hamann \& L. R. Squire, 1997), suggesting that the sense of familiarity used to make a recognition memory judgment is not based on the same mechanism responsible for repetition priming. However, the recognition tests previously used may have discouraged the use of familiarity and encouraged reliance on episodic memory. This issue was addressed in 5 experiments with E.P., 3 other amnesic patients with hippocampal damage, and 8 healthy controls. In Experiments 1-3, which were designed to discourage the use of episodic memory, the amnesic patients were impaired and E.P. performed at chance. In Experiments 4 and 5A, a stem-completion priming task was combined with a recognition memory task on each trial. E.P.'s priming was intact, yet his recognition memory performance was at chance. This suggests that although recognition memory judgments may be made on the basis of familiarity, repetition priming is not the source of this feeling of familiarity.
\end{abstract}

When processing a stimulus item, a recent encounter with the same item or a perceptually similar item facilitates this processing-a phenomenon known as repetition priming (RichardsonKlavehn \& Bjork, 1988; Schacter, Chiu, \& Ochsner, 1993). Repetition priming (as illustrated by tasks like stem completion and perceptual identification) and other forms of nondeclarative (Squire, 1992) or implicit (Schacter, 1992) memory have been dissociated from recognition and recall (declarative or explicit memory) in both normal volunteers (Jacoby \& Dallas, 1981; Roediger \& McDermott, 1993; Schacter, 1992; Tulving, Schacter, \& H. Stark, 1982) and amnesic patients (Hamann \& Squire, 1997; Squire \& Knowlton, 1995). Some have viewed these dissociations in the context of dual-process theories of recognition, according to which recognition memory is composed of two components: explicit recollection and familiarity (Gardiner \& Java, 1993; Jacoby, 1991; Mandler, 1980, 1989). These theories propose that a single underlying factor is both the source of repetition priming effects

Craig E. L. Stark, Department of Psychiatry, University of California, San Diego; Larry R. Squire, Medical Research Service, Veterans Affairs Medical Center, San Diego, California, and School of Medicine, University of California, San Diego.

This research was supported by the Medical Research Service of the Department of Veterans Affairs, National Institute of Mental Health (NIMH) Grant MH24600, the National Alliance for Research on Schizophrenia and Depression, the McDonnell-Pew Center for Cognitive Neuroscience at the University of California, San Diego, and NIMH Training Grant T32 AG00216-07. We thank J. Frascino, J. Zouzounis, and T. Rickard for assistance with data collection.

Correspondence concerning this article should be addressed to Larry $\mathbf{R}$. Squire, Veterans Affairs Medical Center 116A, 3350 La Jolla Village Drive, San Diego, California 92161. Electronic mail may be sent to LSquire@ ucsd.edu. and one of the bases for the feeling of familiarity that is used during recognition memory judgments.

An alternative view holds that repetition priming and recognition are independent of one another. Although the form of memory responsible for repetition priming is present during a recognition memory task, and although a feeling of familiarity is a component of recognition memory judgments, the form of memory that supports repetition priming is not the source of the familiarity component of recognition memory (Schacter, 1992; Schacter \& Buckner, 1998; Squire, 1992; Squire, Knowlton, \& Musen, 1993; Wagner, Gabrieli, \& Verfaellie, 1997). The neuropsychological evidence is consistent with this view. Damage to the hippocampus and related medial temporal lobe structures results in amnesia. Numerous studies have shown a dissociation between intact repetition priming and impaired recognition memory in amnesic patients (e.g., Haist, Shimamura, \& Squire, 1992; Hamann \& Squire, 1997; Reber \& Squire, 1999). Further, focal occipital lobe lesions can impair performance on visuoperceptual priming tasks while leaving recognition memory intact (Gabrieli, Fleischman, Keane, Reminger, \& Morrel, 1995; Keane, Gabrieli, Mapstone, Johnson, \& Corkin, 1995). Additionally, although increasing perceptual fluency (a term often used to describe what is changed during perceptual repetition priming) increases the probability that both healthy controls (e.g., Johnston, Dark, \& Jacoby, 1985; Whittlesea, 1993) and amnesic patients (Verfaellie \& Cermak, 1999) will endorse an item during a recognition memory test, the improvement is similar for both studied and nonstudied items. Manipulating perceptual fluency can shift bias but does not reliably increase recognition memory accuracy (see also Reber \& Squire, 1999).

The severely amnesic patient E.P. provides particularly compelling evidence for this alternative view. E.P. has severe anterograde and retrograde amnesia (Hamann \& Squire, 1997; Reed \& Squire, 1998; Squire \& Knowlton, 1995) and has scored at chance on every test of delayed recognition memory that he has been given. 
Yet, he exhibits completely intact stem completion and perceptual identification priming (Hamann \& Squire, 1997) and completely intact category learning of dot patterns (Squire \& Knowlton, 1995). In one study (Hamann \& Squire, 1997), E.P. had a mean discriminability score (d') of 0.067 (chance equals 0 ) across six yesino recognition memory tests and a mean percentage correct of $52 \%$ (chance equals $50 \%$ ) across six forced-choice recognition memory tests. In contrast, his performance was identical to that of healthy volunteers on both a stem-completion task and a perceptual identification task that involved the same stimuli.

These findings suggest that the memory that results in repetition priming is not available as a source of familiarity-based recognition. E.P.'s recognition memory was not benefitted by his intact repetition priming. However, it is possible that the conventional recognition tests used by Hamann and Squire (Hamann \& Squire, 1997) discouraged the use of familiarity and encouraged reliance on episodic memory. To explore this possibility, we designed five experiments that encouraged the use of familiarity and discouraged the use of episodic memory.

\section{Experiment 1}

In contrast to the experiments reported by Hamann and Squire (1997), an explicit effort was made in this study to encourage the use of familiarity as a basis for recognition memory judgments. Specifically, a speeded, forced-choice recognition memory paradigm was used at test. Participants were instructed to make their judgments as quickly as possible, and a time limit was imposed on each trial.

\section{Method}

Participants. E.P. is a 75 -year-old retired laboratory technician with 12 years of education who, in 1992, suffered extensive bilateral damage to the medial temporal lobes as the result of herpes simplex encephalitis. The damage extends caudally from the temporal pole and damages bilaterally the perirbinal cortex, the amygdaloid complex, the entorhinal cortex, the parahippocampal cortex, and the hippocampal region (CA fields, dentate gyrus, and subicular complex). The lesion also extends laterally to include the fusiform gyrus at some levels (Reed \& Squire, 1998; Schmolck, Stefanacci, \& Squire, in press). In addition to E.P., 3 other amnesic patients with hippocampal formation damage also participated (A.B., P.H., and L.J.; see Table 1). All 4 patients had participated in the Hamann and Squire (1997) experiments, and additional neuropsychological data appear there and elsewhere (Hamann \& Squire, 1995). Finally, 8 healthy volunteers (2 men, 6 women; mean age $=74.6$ years; mean education $=11.9$ years) served as a control group. Six of the 8 controls had also participated in the experiments reported by Hamann and Squire (1997).

The same amnesic patients and controls participated in Experiments 1-5, with the exception of 1 control who was unavailable for Experiments 4 and 5.

Materials. Six of the 24-word lists used by Hamann and Squire (1997) were used in Experiment 1. Three of these lists were used as a source of study items, and the remaining three were used as a source of foils. As the performance of patient E.P. is the primary focus of this study, all participants received the exact same stimuli in the same order as did E.P.

Procedure. The experiment consisted of a study phase and a test phase In the study phase, participants were shown a list of 24 words, with a duration of $3 \mathrm{~s}$ and an intertrial interval (ITI) of $0.5 \mathrm{~s}$, and asked to name each word aloud. After a 5-min delay, the test phase began. The test phase consisted of a forced-choice recognition memory task in which participants were shown two words beside each other on the computer screen. One of the words was a previously studied item (target) and the other was not (foil). Above the two words were the instructions, "Which old?", and participants were asked to indicate with a keypress which word was on the previously studied list. They were asked to make their judgments as rapidly as possible and to "go with their gut feeling" if they did not immediately know the answer. If their response was not made within $1.5 \mathrm{~s}$, the computer would beep, indicating that they should try to respond more rapidly. After the ITI, another pair of words appeared until all 24 pairs had been shown For each participant, the experiment was repeated a total of three times in one session, with different materials for each test.

Before the experiment, a practice task was administered to ensure that participants could read the two stimuli and perform a speeded, forcedchoice decision task. In the practice task, participants identified which of two words shown on the screen named an animal. With a 1.5-s stimulus duration and response window, and a 0.5-s ITI, E.P. performed reliably with a list of 24 word pairs. His performance noticeably worsened with more rapid presentations. After one or two runs through the practice task, all participants were able to make responses reliably within these time constraints.

\section{Results}

Figure 1 shows recognition memory performance for the three groups in terms of overall percentage correct, together with the forced-choice recognition memory data from Hamann and Squire (1997). The healthy volunteers were correct on $84 \%$ of their judgments, $t(7)=11.0, p<.001$, versus chance. The 3 amnesic patients were impaired relative to controls $(65 \%$ correct), $t(9)=2.8, p<.02$, and did not differ significantly from chance, $t(2)=1.8, p=.2$. Finally, across the three test repetitions, E.P.'s performance was not above chance, averaging only $43 \%$ correct on this task.

Table 1

Characteristics of Amnesic Parients

\begin{tabular}{|c|c|c|c|c|c|c|c|c|}
\hline \multirow[b]{2}{*}{ Patient } & \multirow[b]{2}{*}{ Age } & \multirow[b]{2}{*}{ Education } & \multirow[b]{2}{*}{ WAIS-R IQ } & \multicolumn{5}{|c|}{ WMS-R } \\
\hline & & & & Attention & Verbal & Visual & General & Delay \\
\hline E.P. & 75 & 12 & 103 & 94 & 59 & 82 & 68 & 56 \\
\hline A.B. & 60 & 20 & 104 & 87 & 62 & 72 & 54 & $<50$ \\
\hline P.H. & 75 & 19 & 115 & 117 & 67 & 83 & 70 & 57 \\
\hline L.J. & 60 & 12 & 98 & 105 & 83 & 60 & 69 & $<50$ \\
\hline
\end{tabular}

Note. The Wechsler Adult Intelligence Scale-Revised (WAIS-R) and the indices of the Wechsler Mernory Scale-Revised (WMS-R) yield a mean score of 100 in the normal population with a standard deviation of 15. L.J. is female and the other patients are male. 


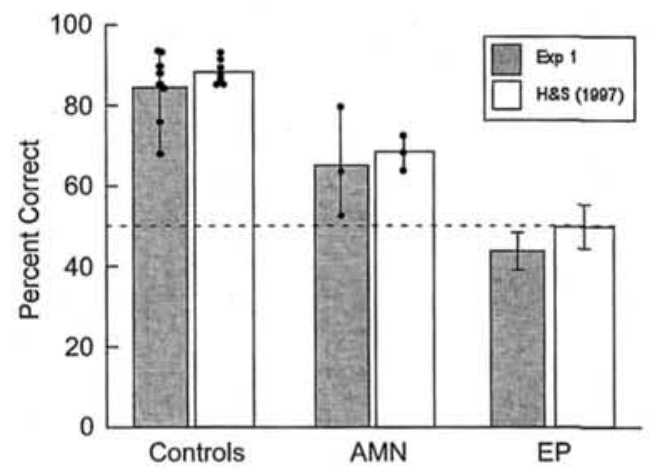

Figure 1. Percentage of correct scores on the speeded, forced-choice recognition memory test of Experiment 1 (Exp. 1, grey bars) for controls $(n=8)$, amnesic patients (AMN, $n=3$ ), and E.P. For comparison, performance on the forced-choice recognition memory task of Hamann and Squire (1997) is shown as well (H \& S [1997], white bars). For the controls and the AMN group, circles show the average score for each participant on three different tests. E.P.'s score is his mean $( \pm S E M)$ for the same three tests. The dotted line represents chance performance. Despite the time constraint and the encouragement to rely on "gut feeling," E.P.'s recognition memory performance was at chance.

\section{Experiment 2}

Experiment 1 demonstrated that requiring recognition memory judgments to be made as rapidly as possible did not elevate E.P.'s performance above chance levels. As discussed, the time available to make each recognition memory judgment was the minimum time in which he could read two words, make a two-choice decision based on the words, and press a key indicating his choice. It is unlikely, therefore, that further limiting the time available to make the decision could yield above-chance recognition memory performance.

In Experiment 2, we encouraged the use of familiarity in a different way, by modifying the instructions given in the test phase. At test, no reference was made to the previous study phase, and participants were asked to decide (as quickly as possible) which of two words was "more familiar." Experiment 2 is therefore not a conventional test of recognition memory. Rather, Experiment 2 asks whether, for E.P., judgments of familiarity can be altered by the study task. That is, Experiment 2 attempts to ascertain whether E.P.'s familiarity judgments (of the kind that could potentially contribute to recognition memory decisions) can be influenced by a prior study task.

We expected that healthy controls would recall having seen words in the study phase and would most likely perceive this as a recognition memory test in spite of the instructions. However, E.P.'s amnesia is so severe that he has no measurable episodic memory. Without any memory of the study episode to guide him, and given instructions that made no reference to the study episode, we expected that E.P. would use feelings of familiarity, rather than episodic memory, when making his judgments.

\section{Method}

Participants. The same individuals who had participated in Experiment 1 also participated in Experiment 2.
Materials. Six of the 24-word lists used by Hamann and Squire (1997) were used in Experiment 2. Three of the lists were used as a source of study items, and the remaining three were used as a source of foils. Again, all of the participants received the exact same stimuli in the same order as E.P.

Procedure. The experimental procedure was identical to that of Experiment 1 except that the instructions given during the test phase were modified. At test, volunteers were informed that some words "may seem more familiar than others." Instead of asking volunteers to quickly choose which of the two presented words was on the study list, we asked them to quickly choose the word that was "more familiar." Above the pair of words on each test trial the phrase, "Which familiar?" replaced the phrase, "Which old?" that was used in Experiment 1 . In this way, volunteers were encouraged to use familiarity as the basis for their speeded judgments. Note that at no point during the test phase was any reference made to the earlier study phase. For each participant, the test was repeated a total of three times in one session, with different materials on each occasion.

\section{Results}

Figure 2 shows recognition memory performance for the three groups in terms of overall percentage correct across the three tests. The healthy volunteers were correct on $85 \%$ of their judgments, $t(7)=10.8, p<.001$, versus chance. The amnesic group averaged $68 \%$ correct and was impaired relative to controls, $t(9)=3.0, p<$ .05 . Their recognition accuracy was also above chance levels, $t(2)=9.2, p<.05$. Across the three tests, E.P. was again not above chance, averaging only $47 \%$ correct. Approximately 1 year after his initial testing, E.P. was again given three tests in this same paradigm to determine whether an imbalance in the preexperimental familiarity of the test stimuli could have obscured an effect of the study task on familiarity judgments. Study and foil items were exchanged for these tests. Although E.P.'s average performance across all six tests rose slightly, to $55 \%$ correct, this result was largely due to one outlier (75\% correct). His performance was still not reliably above chance $(p=.34)$, and his median score across all six tests was $49 \%$ correct.

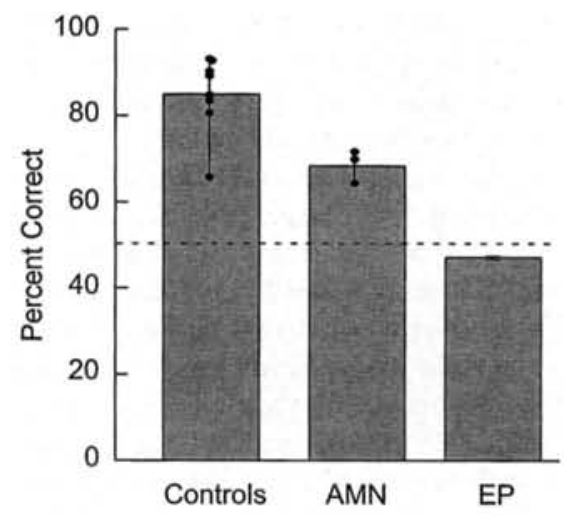

Figure 2. Percentage of correct scores on the speeded, forced-choice familiarity-based recognition memory task of Experiment 2 for controls $(n=8$ ), amnesic patients (AMN, $n=3$ ), and E.P. For the controls and the AMN group, circles show the average score for each participant on three different tests. B.P.'s score is his mean ( $\pm S E M$ ) for the same three tests. The dotted line represents chance performance. Despite instructing participants to base judgments on a feeling of familiarity, E.P.'s performance was at chance. 
Postexperimental interviews indicated that controls perceived the experiment as a test of recognition memory and did not base their judgments purely on a feeling of familiarity. For example, when asked what "familiar" meant, one control replied, "Familiar meant I saw it before on the screen." Another responded, "Familiar means the word I recognized from the words I read earlier." Two of the 3 amnesic patients (L.J. and A.B.) similarly perceived the experiment as a thinly disguised recognition memory test. In the postexperimental interview, A.B. defined "familiar" by saying, "I was interpreting 'most familiar' as the one I had seen before." In contrast, both the most severely impaired of the amnesic group (P.H.) and E.P. gave no indication that they remembered the study phase or that they were basing their judgments on anything but familiarity. During one of the study phases, E.P. did predict that his memory would later be tested, saying, "I bet you're going to test me on these later." However, after the last test item, when asked what he was using to make his decision, E.P. replied that he picked the one that was "more common" and gave no indication that he remembered having seen the words earlier.

\section{Experiment 3}

Experiment 2 demonstrated that explicit instructions to make speeded forced-choice judgments based on familiarity did not elevate E.P.'s performance above chance levels. In Experiment 3, participants were again asked to make rapid familiarity judgments, but the forced-choice paradigm used in Experiment 2 was replaced by a yes/no paradigm in which judgments were made on single items. As was the case for Experiment 2, Experiment 3 does not provide a conventional test of recognition memory. Rather, Experiment 3 attempted to directly encourage the use of familiarity in making judgments.

Experiment 3 was initially attempted with E.P. using three lists of stimuli from the same population as Experiments 1 and 2 (the word lists used by Hamann \& Squire, 1997). When asked to make yes/no familiarity judgments on these words, E.P. responded "yes" to every item on the first two lists, repeatedly commenting, "This is easy: these are all familiar words." Even when instructed to respond "yes" if the word seemed "more familiar than most words," E.P. generated too few "no" responses to allow for any difference to emerge in his treatment of study items and foils.

The words used by Hamann and Squire (1997) were relatively familiar words, having a maximum Kucera and Francis frequency of 895 and a mean of 52 (Kucera \& Francis, 1967). In responding "yes" to virtually all of these items, E.P. demonstrated that when asked to make judgments of familiarity, he responds on the basis of familiarity and does not view the task as a thinly veiled test of his memory (as healthy control volunteers and 2 of the amnesic patients did in Experiment 2.) In an effort to reduce the subjective familiarity of the words (and thereby reduce the number of "yes" responses), a different set of words was used (Coltheart, 1981), with lower Kucera and Francis frequency scores (maximum $=20$, $M=10$ ).

\section{Method}

Participants. The same individuals who had participated in Experiments 1 and 2 also participated in Experiment 3.

Materials. Twelve lists of 24 words were drawn from the abovementioned set. Word length ranged from four to seven letters and included words less familiar than those used in Experiments 1 and 2 (e.g., austere, zeal, creed, inquest). Six of the lists served as study lists, and six served as foils. As with Experiments 1 and 2, all participants received the exact same stimuli in the same order as did E.P.

Procedure. The study phase was identical to that used in Experiments 1 and 2, and the test phase was similar to that used in Experiment 2. However, instead of asking volunteers which of two words was "more familiar," Experiment 3 used a speeded yes/no paradigm. On each trial, a single word was presented in the middle of the screen with the question "Familiar?" printed above it. Participants were asked to press a key marked "yes" if the word "felt familiar" to them and to press a key marked "no" if it did not. They were informed that some words might feel more familiar than others. Participants were thus encouraged to use familiarity as the basis for their judgments. As in Experiments 1 and 2, participants were encouraged to respond quickly with their first impression, and a 1.5-s time limit was imposed on each trial. Note that at no point during the test phase was any reference made to the earlier study phase. For each participant, the experiment was repeated a total of six times over 2 days, with different materials on each occasion.

\section{Results}

Figure 3 shows recognition memory performance for the three groups in terms of $d^{\prime}$. The healthy volunteers were correct on $81 \%$ of their judgments, and obtained an average $\mathrm{d}^{\prime}$ score of 1.85 , $t(7)=11.4, p<.001$, versus a chance score of 0 . The amnesic group averaged $65 \%$ correct, with a corresponding $\mathrm{d}^{\prime}$ of 1.08 . Their performance was marginally impaired relative to controls, $t(9)=2.2, p=.057$, and did not significantly differ from chance levels, $t(2)=1.1, p=.11$. Across the six tests, E.P. was correct $51.9 \%$ of the time, with a corresponding $\mathrm{d}^{\prime}$ of 0.2 . A onesample $t$ test on the $\mathrm{d}^{\prime}$ measures obtained from each of the six tests $(-0.03,0.77,0.48,0.0,0.0,0.0)$ showed no deviation from chance performance, $t(5)=1.5, p=.2$. Approximately 1 year after his initial testing, E.P. was again given six tests in this paradigm to determine whether an imbalance in the preexperimental familiarity of the test stimuli was obscuring an effect of the study task on his familiarity judgments. Study and foil items were exchanged for these tests. E.P.'s average performance across all 12 tests remained

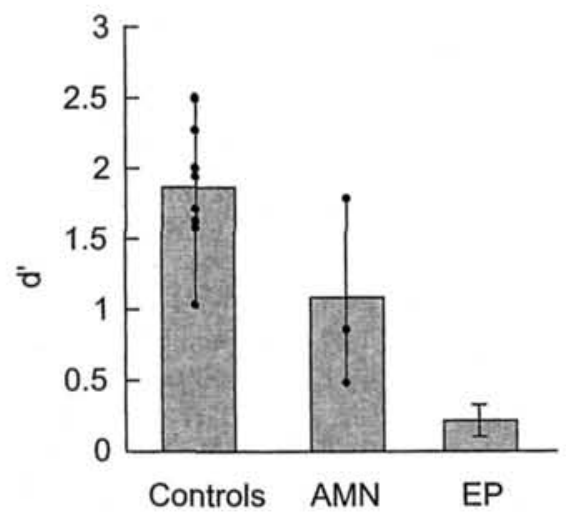

Figure 3. Discriminability ( $\left.\mathrm{d}^{\prime}\right)$ on the speeded yes/no familiarity-based recognition memory task of Experiment 3 for controls $(n=8)$, amnesic patients (AMN, $n=3$ ), and E.P. For the controls and the AMN group, circles show the average score for each participant on six different tests. E.P.'s score is his mean ( $\pm S E M)$ for the same six tests. A $\mathrm{d}^{\prime}$ of 0 represents chance performance. Instructing participants to endorse words that "felt familiar" did not elevate E.P.'s performance. 
at chance $(p=.45)$ with an average score of $50.7 \%$ correct and a corresponding $\mathrm{d}^{\prime}$ of 0.08 (median $=0.0$ ).

Postexperimental interviews again indicated that the controls perceived the experiment as a recognition memory test. Interviews of 4 of the controls indicated that in each case, their responses were based on whether they remembered having seen the word during the study phase. One volunteer said words were "definitely familiar as if I'd studied them." Another commented, "I had just seen it (a word) in the list of words I just read." The same 2 amnesic patients that perceived Experiment 2 as a recognition memory test also perceived Experiment 3 as a recognition memory test. During the test sessions, L.J. routinely commented, "seen that one . . . didn't see that one." In the interview, A.B. commented that he was trying "to decide if I'd seen it before." In contrast, P.H. (whose d' score of 0.51 was the lowest of the amnesic group) did not view this as a test of recognition memory. In the interview, he commented that "most of them were all familiar--just a couple out of the ordinary." When asked to define "familiar," P.H. said, "if it is known to me ... [Experimenter: 'If it is in your vocabulary?'] ... Yes." As in Experiment 2, E.P. gave no indication that he remembered the study phase or that he was basing his judgments on anything but a feeling of familiarity, defining "familiar" as "common."

\section{Experiment 4}

In Experiment 4, we attempted to provide E.P. with whatever information his intact nondeclarative memory could provide by making this information as accessible as possible to him when he was making recognition memory judgments. During the test phase, each test trial consisted of a stem-completion task followed immediately by a forced-choice recognition test. In the stemcompletion portion of the trial, a three-letter word stem was presented with the instruction to complete the stem to form the first word that comes to mind. The stem could always be completed to form a studied word. In the recognition portion of the trial, two words were presented: the studied item that completed the stem and a matched foil that also completed the stem. Because E.P. exhibits intact repetition priming, we expected that he would often complete the stem with the studied item. Several seconds after completing the stem, the studied item and a foil were presented together for a forced-choice recognition memory test. On many of the trials, he would have generated the correct answer (the studied item) in response to the stem-completion probe just before the recognition memory test. The question of interest was whether his recognition memory performance would remain at chance on those trials when he had just demonstrated intact priming for the same word.

\section{Method}

Participants. The same individuals who had participated in Experiments 1-3 also participated in Experiment 4, with the exception of 1 control who was unavailable.

Materials. Stem-completion norms for 120 three-letter word stems (Graf, Squire, \& Mandler, 1984) were collected from 110 University of California, San Diego (UCSD) undergraduate students. The word stems were randomly divided into six lists of 20 word stems. For each of the six lists, the two most frequent completions of the stems were alternately assigned to a pair of matched completion lists. Half of the items on each completion list were therefore the most frequent completions to the word stems, and half were the second most frequent completions, resulting in two lists of words whose mean completion rates from the stem list were approximately equal. To match the completion lists more closely, the mean and variance of completion rates across the 12 lists were then equated by exchanging items across lists. For each of these matched completion lists, one list served as study items and one as foils.

Procedure. The study phase was similar to that used in the previous three experiments. Participants viewed a list of 20 words (e.g., motel) presented one at a time. In the test phase, each of 20 trials began by presenting one of the three-letter stems (e.g., mot_) along with instructions to "Complete this word beginning to form the first word that comes to mind." Once the participant had verbally completed the stem to form a word, the screen was cleared and a pair of words (one from the study list and one from the matched foil list), appeared on the screen (e.g., motel, motor). Participants were then asked, "Which word did you see on the list 10 minutes ago?" and were encouraged to make their responses quickly (no fixed time limit was imposed, however). After their response, a $500-\mathrm{ms}$ ITI preceded the next trial. To generate sufficient data, a total of six study-test sessions were completed over 2 days. All participants received the exact same stimuli in the same order as did E.P.

\section{Results}

Figure $4 \mathrm{a}$ shows the priming scores for all three groups of participants. Controls completed the stem to the study item (e.g., motel) with a probability of 0.46 , and they produced the matched nonstudied item (e.g., motor) with a probability of 0.17 . The priming score was taken to be the difference, 0.29 . The amnesic group had an average priming score of $0.18(0.38$ vs. 0.2$)$. E.P. demonstrated normal levels of priming across his six tests, averaging 0.26 ( 0.46 vs. 0.2$)$. His priming score was well within the range of the control scores (control $95 \%$ confidence interval $=0.19-0.39$ ) and only 0.31 standard deviations from the control mean.

Figure $4 \mathrm{~b}$ shows performance on the forced-choice recognition memory portion of the task. The healthy controls were correct on $80 \%$ of their judgments, $t(6)=10.1, p<.001$, versus chance. The amnesic group averaged $62 \%$ correct and was impaired relative to controls, $t(8)=3.2, p<.05$. Moreover, their recognition accuracy
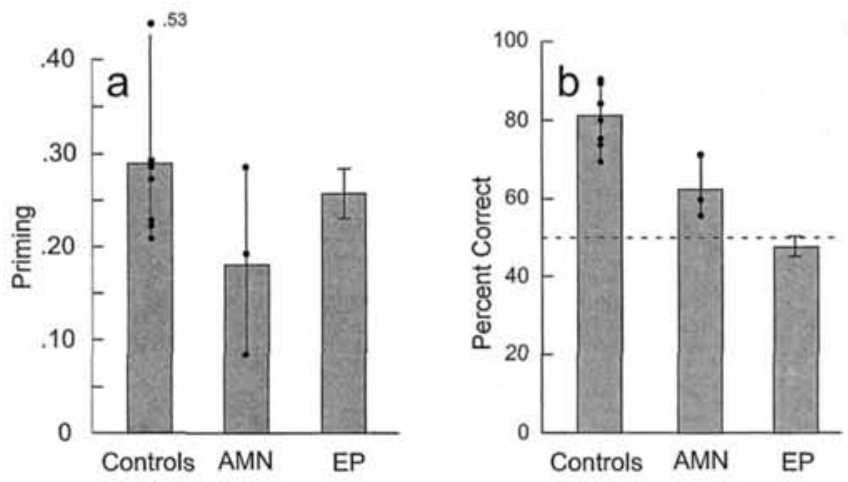

Figure 4. Performance on the stem-completion task (a) and the forcedchoice recognition memory task (b) of Experiment 4 for controls $(n=7)$. amnesic patients (AMN, $n=3$ ), and E.P. For the controls and the AMN group, circles show the average score for each participant on six different tests. E.P.'s score is bis mean ( $\pm S E M$ ) for the same six tests. The dotted line shows chance performance. Giving E.P. access to his intact priming for each item immediately before the recognition probe failed to elevate his performance above chance. 
was not significantly different from chance levels, $t(2)=2.6, p=$ 11. Finally, across the six tests, E.P. also did not score above chance, averaging only $48 \%$ correct.

Recognition performance versus stem-completion performance is shown in Table 2 for all three groups. When the controls and amnesic patients completed the word stem to form the study item, their probability of choosing the studied word in the forced-choice recognition test was above chance (binomial $p s<.001$ ). Moreover, when they completed the word stem to form the matched foil word that was presented in the forced-choice recognition test, controls showed a nonsignificant trend to choose the foil word during recognition (binomial $p=.18$ ). Similarly, the amnesic patients chose the foil more often than the studied item on these trials (binomial $p<.01$ ). These findings suggest that, for the controls and amnesic patients, the stem-completion task and the recognition memory task were not independent. This result could occur if both tasks drew on a single memory trace or if both tasks were influenced by a common factor (e.g., the attention paid to each item at study). Alternatively, it is possible that the words that were produced in response to the stem completion probes (and any feelings of familiarity associated with these words) served as cues for recognition memory. If so, it would not simply be the case that priming benefitted recognition. Rather, the participants might have a bias in the recognition task to choose the word that they had just produced in the stem-completion task (see Experiments 5A, 5B, and Table 4).

Patient E.P. performed differently than the controls and the other amnesic patients. He had a bias not to choose the word he had generated in the stem-completion portion of the trial. Of the 55 trials in which E.P. completed the word stem to the studied item, he incorrectly chose the foil on 42 trials during the recognition portion $(76 \%$, binomial $p<.001)$. Similarly, on 20 of the 24 trials (83\%) in which E.P. completed the stem to the foil item, he correctly chose the target item during recognition $(p<.005)$. His bias for choosing the other word was similar regardless of whether he generated the study item or the foil (binomial $p=.7$ ). Thus, instead of using his intact priming to facilitate his recognition, E.P.'s bias worked against recognition accuracy. E.P. tended to choose a word other than the word he had generated in the stem completion phase.

\section{Experiment $5 \mathrm{~A}$}

In Experiment 4, E.P. demonstrated intact priming for an item and then, immediately thereafter, demonstrated no recognition memory for the same item. Despite having frequently uttered the correct word $5 \mathrm{~s}$ earlier in response to the stem-completion probe, E.P. failed to use this information to facilitate his recognition memory judgments. One difficulty in interpreting these results comes from the fact that E.P. demonstrated a strong bias in the recognition task. Specifically, he avoided choosing words he had just produced in the stem-completion task. Although this bias does not support the idea that priming can support or facilitate recognition memory judgments, it is possible that E.P.'s bias might have obscured a contribution of priming to recognition.

Experiment 5A addressed this possibility. Instead of presenting participants with a forced-choice recognition memory task using the two most likely completions to the just-completed stem (as in Experiment 4), a yes/no paradigm was adopted. After completing the word stem to form a word, participants decided whether this word was on the list they had studied $10 \mathrm{~min}$ earlier. We thus saught to determine whether completing the word stem to form the studied item, immediately before the recognition memory test, would facilitate E.P.'s recognition memory.

\section{Method}

Participants. E.P. and the healthy control volunteers who participated in Experiment 4 also participated in Experiment 5A.

Materials. The six lists of 20 words used in Experiment 4 were also used in Experiment 5A ( 6 months later). Three of the lists served as study items, and three of the lists served as foils in the test phase. Two of the lists used as study items had served as foils in Experiment 4, and one list had served as targets.

Procedure. The study phase was similar to that used in the previous experiments. Participants viewed a list of 20 words (e.g., motel) presented one at a time. In the test phase, each of the 40 trials began with the presentation of a three-letter stem (e.g., mot_), with instructions to "Complete this word beginning to form the first word that comes to mind." Haif of the stems could be completed to form study items and half could not. Once the participant had named a word that completed the stem, the experimenter asked whether the word just generated was on the list of words the participant had recently studied. For example, if the participant completed the stem mot_ with the word motel, the experimenter asked, "Was motel on the list of words you studied ten minutes ago?" For each participant, the experiment was repeated a total of three times in one session, with different materials. All participants received the same stimuli in the same order.

\section{Results}

Figure 5 shows the priming and recognition memory scores. Priming scores were first calculated by subtracting the baseline

Table 2

Recognition Memory Performance Versus Stem Completion Performance (Experiment 4)

\begin{tabular}{|c|c|c|c|c|c|c|c|c|c|}
\hline \multirow[b]{3}{*}{ Recognition ${ }^{\mathrm{I}}$} & \multicolumn{9}{|c|}{ Stem completion ${ }^{b}$} \\
\hline & \multicolumn{3}{|c|}{ Controls } & \multicolumn{3}{|c|}{ Amnesic patients } & \multicolumn{3}{|c|}{ E.P. } \\
\hline & Studied & Foil & Other & Studied & Foil & Other & Studied & Foil & Other \\
\hline Correct & 54.9 & 8.1 & 33.6 & 41.0 & 6.0 & 28.0 & 13 & 20 & 24 \\
\hline Incorrect & 0.8 & 12.4 & 10.1 & 4.7 & 18.0 & 22.3 & 42 & 4 & 17 \\
\hline
\end{tabular}

Note. Numbers are the average number of trials in each of the six response categories (out of a total of 120).

${ }^{a}$ In the forced-choice recognition test, participants could choose the study item (correct) or the matched foil item (incorrect). ${ }^{b}$ Word stems could be completed to form the studied item, the matched foil item, or some other valid word. 
probability of completing the stems to the study items $(0.23$, based on results from 110 UCSD undergraduates) from the observed probability of completion. On those trials in which the word stem could be completed to form a study item, controls produced the study item with a probability of 0.49 (priming score $=0.26$ ). E.P.'s probability of producing the study item was 0.45 (priming score $=0.22$ ). E.P.'s priming score was normal, corresponding exactly to the median score of the controls.

The recognition scores were very different. Controls scored $72 \%$ correct, but E.P. scored only $53 \%$ correct across his three tests. His three scores were not better than chance, $t(2)=0.9, p=.5$, and were below the mean score of the controls, $t(2)=5.1, p<.05$. The finding of interest was that successfully completing the word stem to form the study word did not affect E.P.'s recognition performance (see Table 3). In the stem completion phase, E.P. produced the study word on 27 trials (out of 60 trials in which a study item could have been generated). In response to the recognition memory question, he then correctly responded "yes" on 13 of these trials $(48 \%)$, and incorrectly responded "no" on 14 trials (52\%). Despite the fact that his priming was normal and that he had just generated the study item in response to the stem-completion probe, he did not use that information to say "yes" more often than "no" in response to the recognition memory question that followed immediately thereafter. In contrast, on the average of 29.4 trials in which the controls completed the word stems to form study items, they correctly responded "yes" to the yes/no recognition memory probe on 24.3 trials and "no" on 5.1 trials ( $83 \%$ correct).

As in Experiment 4, controls were somewhat more likely to indicate that they recognized a word if they had generated it in the stem-completion task. Thus, controls scored $83 \%$ correct $(24.3 /$ 29.4 ) on the recognition memory test when they completed the word stem to the studied word and only $68 \%$ correct $(61.3 / 90.6)$ when they completed the word stem to a nonstudied word (Table 3). E.P., however, showed no such dependence, scoring $48 \%$ correct $(13 / 27)$ when he completed the word stem to the studied item and $55 \%$ correct $(51 / 93$, binomial $p=.4)$ when he completed the word stem to a nonstudied word.
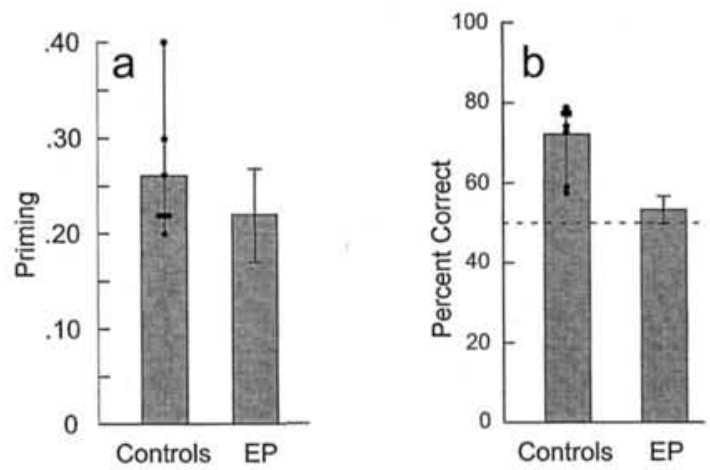

Figure 5. Performance on the stem-completion task (a) and the yes/no recognition memory task (b) of Experiment 5, for controls $(n=7)$ and E.P. For the controls, circles show the average score for each participant on three different tests. E.P.'s score is his mean ( $\pm S E M$ ) for the same three tests. The dotted line shows chance performance. Giving E.P. access to his intact priming for each item immediately prior to the recognition probe failed to elevate his performance above chance.
Table 3

Recognition Memory Performance Versus Stem Completion Performance (Experiment 5A)

\begin{tabular}{|c|c|c|c|c|}
\hline \multirow[b]{3}{*}{ Recognition ${ }^{a}$} & \multicolumn{4}{|c|}{ Stem completion ${ }^{\mathrm{b}}$} \\
\hline & \multicolumn{2}{|c|}{ Controls } & \multicolumn{2}{|c|}{ E.P. } \\
\hline & Studied & Other & Studied & Other \\
\hline Correct & 24.3 & 61.3 & 13 & 51 \\
\hline Incorrect & 5.1 & 29.3 & 14 & 42 \\
\hline
\end{tabular}

Note. Numbers are the average number of trials in each of the four response categories (out of a total of 120 trials in the six tests).

"In the recognition test, participants indicated whether the word generated in response to the stem-completion probe was on the study list. ${ }^{b}$ Word stems could be completed to form the studied item or some other valid word.

\section{Experiment 5B}

In Experiment 5A, recognition memory accuracy for controls was higher when they completed the word stem to the studied word than it was when they completed the word stem to a nonstudied word (Table 3 ). This finding suggests some degree of dependence between repetition priming and recognition memory performance. From the data, however, one cannot know whether completing the stem to the studied word increased recognition memory accuracy or whether completing the word to a nonstudied stem decreased recognition memory accuracy. Experiment 5B addressed this issue by presenting the controls with the identical recognition memory test as in Experiment $5 \mathrm{~A}$ but without the stem-completion component of the experiment.

\section{Method}

Participants. Six of the 7 healthy control volunteers from Experiment 5 A participated.

Materials. The same six lists of 20 words used in Experiment 5A were also used in Experiment 5B.

Procedure. Experiment 5B took place approximately 1 year after Experiment 5A. The study phase was identical to that of Experiment 5A. Each participant received the same stimuli in the same order as in Experiment SA. Unlike Experiment 5A, the test phase did not include a stemcompletion task and consisted only of a yes/no recognition memory test with $\mathbf{4 0}$ words. For each participant, the recognition memory test was the same test that he or she had received in Experiment 5A. On average, the recognition memory test was composed of 9.8 targets and 30.2 foils. Whatever word the participant had generated in response to the stemcompletion probe of Experiment $5 \mathrm{~A}$ was used as the recognition memory stimulus in Experiment $5 \mathrm{~B}$ (as it was in Experiment $5 \mathrm{~A}$ ). The only difference between the recognition memory task of Experiment 5A and 5B, therefore, was the presence of the stem-completion task in Experiment 5A. Therefore, the precise number of targets and foils varied for each participant and for each of the three repetitions of the experiment.

\section{Results}

The probability of responding "yes" or "no" to the recognition memory probe, conditionalized on whether the probe was a studied item, is shown in Table 4. In Experiment 5A, if the recognition memory probe was a studied item, the probability of responding "yes" was 0.84 and the probability of responding "no" was 0.16 . In 
Expcriment $5 \mathrm{~B}$, the corresponding probabilities remained unchanged at 0.86 and 0.14 , respectively. When the recognition memory probe was a nonstudied item, the probability in Experiment $5 \mathrm{~A}$ of responding "yes" was 0.34 and the probability of responding "no" was 0.66 . In Experiment $5 \mathrm{~B}$, however, the corresponding probabilities shifted to 0.17 and 0.83 . In contrast to the findings in Experiment 5A, controls in Experiment 5B were as accurate at rejecting nonstudied items as they were at accepting studied items. This resulted in an increase in the overall $\mathrm{d}^{\prime}$ from 1.52 in Experiment 5A to 2.24 in Experiment $5 B, t(5)=3.6$, $p<.05$. Thus, the inclusion of the stem-completion task in Experiment $5 \mathrm{~A}$ reduced recognition memory accuracy specifically for trials in which a nonstudied item was generated. Recognition accuracy was already high (0.86), and generating a studied word in the stem-completion task did not improve this score. However, generating a nonstudied word in the stem-completion task reduced recognition accuracy by increasing the probability of false recognition. This finding might be akin to reports that manipulations of perceptual fluency can lead to false recognition (cf. Johnston et al., 1985; Whittlesea, 1993).

\section{Discussion}

In five experiments, we used the most direct methods we could construct for encouraging the use of both familiarity and the information available from repetition priming during recognition memory judgments and familiarity judgments. The experiments focused particularly on the severely amnesic patient, E.P. In every experiment, E.P.'s performance remained at chance. Imposing constraints on the time allowed to make judgments failed to elevate E.P.'s performance above chance (Experiments 1-3). Explicit instructions to base decisions on familiarity failed to elevate his performance above chance (Experiments 2 and 3). Giving E.P. access to his intact repetition priming for each item immediately before the recognition test failed to elevate his performance above

Table 4

Effect of Stem Completion Task on Recognition Memory Performance (Experiments $5 A$ and $5 B$ )

\begin{tabular}{cccccc}
\hline & \multicolumn{1}{c}{$\begin{array}{c}\text { Experiment 5A: } \\
\text { Stem completion } \\
\text { used as } \\
\text { recognition probe }\end{array}$} & & \multicolumn{2}{c}{$\begin{array}{c}\text { Experiment 5B: } \\
\text { Recognition probe }\end{array}$} \\
\cline { 2 - 3 } \cline { 5 - 6 } Recognition" & Studied & Other & Studied & Other \\
\hline "Yes" & 0.84 & 0.34 & & 0.86 & 0.17 \\
"No" & 0.16 & 0.66 & & 0.14 & 0.83 \\
\hline
\end{tabular}

Note. Numbers are the probability of generating a "yes" or "no" response to the recognition probe conditionalized upon stem completion. Data are for the 6 controls who participated in both Experiments 5A and 5B.

${ }^{a}$ In the recognition test of Experiment $5 \mathrm{~A}$, participants indicated whether the word generated in response to the stem-completion probe was on the study list. The items presented in the recognition memory task were the words that had been produced in response to the stem-completion probes. In Experiment 5B, there was no stem-completion task. The items presented in the recognition memory task were, for each control, the words that had been produced in response to the stem-completion probes of Experiment $5 \mathrm{~A}$.

${ }^{b}$ Word stems could be completed to form the studied item or some other valid word. chance (Experiments 4 and 5A). When collapsed across all five experiments, E.P. was correct only $49.9 \%$ (SEM $=2.1 \%$ ) of the time on tests of recognition and familiarity. Yet, E.P. exhibited normal repetition priming-priming that did not facilitate his recognition memory judgments (Experiments 4 and 5A; Hamann \& Squire, 1997). Inasmuch as the status of other forms of priming (e.g., conceptual or semantic) in E.P. are unknown, our findings necessarily apply only to the case of repetition priming. Our data strongly suggest that repetition priming cannot be the basis for the feeling of familiarity used in recognition memory judgments.

In Experiments 2 and 3, the feeling of familiarity was assessed directly by modifying the instructions to make no reference to the study episode and by asking participants to respond on the basis of familiarity. As noted, although this procedure does not provide a conventional test of recognition memory, it does encourage participants (and E.P. in particular) to use familiarity as a basis for making judgments. On the surface, the task appears similar to the "famous names" task. Specifically, both healthy controls (e.g., Dywan \& Jacoby, 1990; Jacoby, Woloshyn, \& Kelley, 1989) and amnesic patients (Squire \& McKee, 1992, 1993) are more likely to judge a name as famous (the "false fame" effect) if they have encountered it recently. One could view the "famous names" task as one in which participants are asked whether they are familiar with a name or not. Thus, in the earlier studies, amnesic patients were more likely to judge a name as famous (or familiar) if they had seen the name recently, but in the present study they were not more likely to designate a word as familiar if they had seen the word recently. One source of this difference may lie in the instructions. Asking participants to judge the fame of names may not be the same as asking them to judge their familiarity. Another source of the difference may lie in the stimuli. Participants have had far more prior experience with words than with the semifamous names used in the earlier studies. It is plausible that the extent to which a study episode influences subsequent judgments may vary according to the "frequency" of the study material, just as low-frequency words yield more repetition priming than high-frequency words (e.g., Jacoby \& Dallas, 1981). The present data cannot address this issue.

In Experiment 4 (and to some extent in Experiment 5A), a relationship was found between performance on the stemcompletion task and performance on the recognition memory task that followed immediately thereafter, In Experiment 4, both controls and the amnesic patients, but not E.P., achieved better recognition accuracy when they generated the target word in the stem-completion task than when they generated the foil word. In Experiment 5A, controls exhibited a similar pattern of performance.

From this, one might conclude that the study task resulted in a memory trace that supports both repetition priming and recognition memory. However, this idea is not consistent with the data First, in Experiment 4, when the foil word was produced in the stem-completion task, the amnesic patients and controls tended in the recognition task to choose the foil word rather than the word from the study list (Table 2). Second, removing the stemcompletion task increased recognition memory accuracy for the foils, but did not alter accuracy for the targets (Experiment 5B). Thus, generating the studied item did not enhance recognition; rather, generating a nonstudied (and not primed) word reduced recognition accuracy (Experiment 5A). Finally, in Experiment 4, 
E.P. was biased to choose the word that he had not generated in the stem completion task. The data from E.P. directly contradict the idea that modifications to a single memory trace result in both a priming effect and an increase in the feeling of familiarity that is used in recognition memory. In summary, we find no evidence for the idea that repetition priming and recognition depend on the same underlying trace or that priming makes a fundamental, automatic contribution to recognition memory judgments.

\section{References}

Coltheart, M. (1981). The MRC psycholinguistic database. Quarterly Journal of Experimental Psychology, 33, 497-505.

Dywan, J., \& Jacoby, L. (1990). Effects of aging on source monitoring: Differences in susceptibility to false alarms. Psychology and Aging, 5, 379-387.

Gabrieli, J. D. E., Fleischman, D. A., Keane, M. M., Reminger, S. L., \& Morrel, F. (1995). Double dissociation between memory systems underlying explicit and implicit memory in the human brain. Psychological Science, 6, 76-82.

Gardiner, J. M., \& Java, R. I. (1993). Recognizing and remembering. In A. Collins, S. Gathercole, M. Conway, \& P. Morris (Eds.), Theories of memory (pp. 163-188). Hillsdale, NJ: Erlbaum.

Graf, P., Squire, L. R., \& Mandler, G. (1984). The information that amnesic patients do not forget. Journal of Experimental Psychology: Learning, Memory and Cognition, 10, 164-178.

Haist, F., Shimamura, A. P., \& Squire, L. R. (1992). On the relationship between recall and recognition memory. Joumal of Experimental Psychology: Leaming, Memory and Cognition, 18, 691-702.

Hamann, S. B., \& Squire, L. R. (1995). On the acquisition of new declarative knowledge in amnesia. Behavioral Neuroscience, 109. 1027-1044.

Hamann, S. B., \& Squire, L. R. (1997). Intact perceptual memory in the absence of conscious memory. Behavioral Neuroscience, 111, 850-854.

Jacoby, L. (1991). A process dissociation framework: Separating automatic and intentional uses of memory. Journal of Memory and Language, 30 , 513-541.

Jacoby, L. L., \& Dallas, M. (1981). On the relationship between autobiographical memory and perceptual learning. Journal of Experimental Psychology: General, 3, 306-340.

Jacoby, L. L., Woloshyn, V., \& Kelley, C. (1989). Becoming famous without being recognized: Unconscious influences of memory produced by dividing attention. Joumal of Experimental Psychology: General. $118,115-125$.

Johnston, W. A., Dark, V. J., \& Jacoby, L. L. (1985). Perceptual fluency and recognition judgments. Joumal of Experimental Psychology: Learming, Memory and Cognition, 11, 3-11.

Keane, M. M., Gabrieli, J. D. E., Mapstone, H. C., Johnson, K. A., \& Corkin, S. (1995). Double dissociation of memory capacities after bilateral occipital-lobe or medial temporal lobe lesions. Brain, 118, 11291148.

Kucera, H., \& Francis, W. N. (1967). Computational analysis of presentday American English. Providence, RI: Brown University Press.

Mandler, G. (1980). Recognizing: The judgment of previous occurrence. Psychological Review, 87, 252-271.
Mandler, G. (1989). Memory: Conscious and unconscious. In P. R. Soloman, G. R. Goethals, C. M. Kelly, \& B. R. Stephens (Eds.), Memory: Interdisciplinary approaches (pp. 84-106). New York: Springer-Verlag.

Reber, P. J., \& Squire, L. R. (1999). Relaxing decision criteria does not improve recognition memory in amnesic patients. Memory and Cognition, 27, 501-511.

Reed, J. M., \& Squire, L. R. (1998). Retrograde amnesia for facts and events: Findings from four new cases, Journal of Neuroscience, 18, 3943-3954.

Richardson-Klavehn, A., \& Bjork, R. A. (1988). Measures of memory. Annual Review of Psychology, 39, 475-542.

Roediger, H. L., \& McDermott, K. (1993). Implicit memory in normal human subjects. In F. Boller \& J. Grafman (Eds.), Handbook of neuropsychology (pp. 63-131). Boston: Elsevier Science Publishers.

Schacter, D. L. (1992). Understanding implicit memory: A cognitive neuroscience approach. American Psychologist, 47, 559-569.

Schacter, D. L., \& Buckner, R. L. (1998). Priming and the brain. Neuron, 20, 185-195.

Schacter, D. L., Chiu, C. Y., \& Ochsner, K. N. (1993). Implicit memory: A selective review. Annual Review of Neuroscience, 16, 159-182.

Schmolck, H., Stefanacci, L., \& Squire, L. R. (in press). Detection and explanation of sentence ambiguity are unaffected by hippocampal lesions but are impaired by larger temporal lobe lesions. Hippocampus.

Squire, L. R. (1992). Memory and the hippocampus: A synthesis from findings with rats, monkeys, and humans. Psychological Review, 99, 195-231.

Squire, L. R., \& Knowlton, B. J. (1995). Learning about categories in the absence of memory. Proceedings of the National Academy of Sciences, USA, 92, 12470-12474.

Squire, L. R., Knowlton, B., \& Musen, G. (1993). The structure and organization of memory. Annual Review of Psychology, 44, 453-495.

Squire, L. R., \& McKee, R. (1992). Influence of prior events on cognitive judgments in amnesia. Journal of Experimental Psychology: Learning, Memory and Cognition, 18, 106-115.

Squire, L. R., \& McKee, R. (1993). Declarative and nondeclarative memory in opposition: When prior events influence amnesic patients more than normal subjects. Memory and Cognition, 21, 424-430.

Tulving, E., Schacter, D. L., \& Stark, H. A. (1982). Priming effects in word-fragment completion are independent of recognition memory. Journal of Experimental Psychology: Learning, Memory and Cognition. 8, 336-342.

Verfaellie, M., \& Cermak, L. S. (1999). Perceptual fluency as a cue for recognition judgments in amnesia. Neuropsychology, 13, 198-205.

Wagner, A. D., Gabrieli, J. D. E., \& Verfaellie, M. (1997). Dissaciations between familiarity processes in explicit recognition and implicit perceptual memory. Journal of Experimental Psychology: Learning, Memory and Cognition, 23, 305-323.

Whittlesea, B. W. A. (1993). Illusions of familiarity. Journal of Experimental Psychology: Learning, Memory and Cognition, 19, 1235-1253.

Received January 8, 1999

Revision received June 10, 1999 Accepted December 5, 1999 